\title{
Tratamento com Resveratrol reduz a Produção de Óxido Nítrico após Isquemia e Reperfusão no Íleo de Ratos Wistar
}

\author{
Stephanie Carvalho Borges ${ }^{1}$, Evandro José Beraldi ${ }^{1}$, Larissa Carla Lauer \\ Schneider ${ }^{1}$, Lia Mara Teobaldo Tironi ${ }^{1}$, Nilza Cristina Buttow ${ }^{1}$ \\ ${ }^{1}$ Universidade Estadual de Maringá - Departamento de Ciências Morfológicas \\ Av. Colombo, 5790 - CEP 87020-900 Maringá - Paraná - E-mail: \\ stephaniecarvalhoborges@hotmail.com
}

\begin{abstract}
RESUMO
Como consequência da injúria causada pela isquemia e reperfusão (I/R) intestinal, a liberação do óxido nítrico (ON) tecidual apresenta destaque devido a seus efeitos danosos. Assim, objetivamos quantificar o óxido nítrico e avaliar o efeito do tratamento com resveratrol em animais submetidos à I/R intestinal. Trinta ratos Wistar foram distribuídos em 5 grupos: grupo C (controle), SC (falso operado controle), STR (falso operado tratado), IRC (isquêmico controle) e IRTR (isquêmico tratado). Os animais foram tratados com $7 \mathrm{mg} / \mathrm{kg}$ de resveratrol. Os níveis de $\mathrm{ON}$ encontrados no íleo foram significativamente maiores no grupo IRC em relação ao grupo $C(p<0,001)$ e os grupos tratados apresentaram níveis de ON próximos aos níveis encontrados nos animais do grupo controle $(p>0,05)$. Embora a $I / R$ promova o aumento de ON presente no tecido, o resveratrol é capaz de diminuir a produção desta molécula podendo beneficiar o tecido atingido.
\end{abstract}

Palavras-chave: Radicais livres, Óxido Nítrico Sintase, Reação de Griess.

\section{INTRODUÇÃO}

O óxido nítrico $(\mathrm{ON})$ é uma molécula gasosa simples e muitas células são capazes de sintetizá-lo através de hemeproteínas da família citocromo P450-like denominadas óxido nítrico sintases (NOS) (WANG; MARDSEN, 1995). Estas enzimas são encontradas em três diferentes isoformas: NOS neuronal (nNOS), NOS endotelial (eNOS) e NOS induzível (iNOS) e estão envolvidas em processos como neurotransmissão, controle da pressão arterial e peristaltismo (TAKAHASHI et al., 2001). Apesar do ON atuar como um importante mensageiro intracelular, altos níveis dessa molécula sintetizados em situações de injúria podem gerar processos inflamatórios e lesar células saudáveis (FILHO; ZILBERSTEIN, 1998).

Com o progressivo envelhecimento da população, as síndromes isquêmicas intestinais vêm se tornando mais frequentes. Isquemia e reperfusão intestinal (I/R) é uma condição grave que comumente ocorre em vários casos clínicos. A restauração do fluxo sanguíneo para um tecido isquêmico pode levar a um dano maior do que aquele originalmente causado pela isquemia (KOHLER et al., 2011). Como consequência da injúria causada pela I/R estão a excitotoxicidade causada pelo excesso de glutamato (CALCINA et al., 2005), o estresse oxidativo, inflamação, liberação de óxido nítrico e consequente morte celular por necrose e/ou apoptose (KASTE, 1997; KIM, 1997; MASSBERG, 1998). 
Londrina 2015

O resveratrol (RSV) é um polifenol que possui propriedades farmacológicas que o faz atuar de forma benéfica sobre os sistemas biológicos possuindo potencial antioxidante, antiinflamatório (ZHANG; LIU; SHI, 2010; SGAMBATO et al., 2001) e neuroprotetor (Wang et al., 2002), além disso é capaz de modular e melhorar as defesas antioxidantes celulares (FREMONTE, 2000; BAUR; SINCLAIR, 2006). Assim, objetivou-se quantificar o óxido nítrico presente no tecido intestinal de animais submetidos a isquemia e reperfusão e avaliar 0 efeito do tratamento com resveratrol nestes animais.

\section{MATERIAL E MÉTODOS}

Foram utilizados 30 ratos albinus da linhagem Wistar (Rattus norvegicus), machos, com peso corporal entre 230 e 250g. Os animais foram divididos em 5 grupos de 6 animais: grupo C (controle não operado), grupo SC (submetido à cirurgia mas sem oclusão da artéria mesentérica superior (AMS) e tratado com veículo), grupo STR (submetido à cirurgia mas sem oclusão da AMS e tratado com resveratrol), grupo IRC (submetido à cirurgia com oclusão da AMS e tratado com veículo) e grupo IRTR (submetido à cirurgia com oclusão da AMS e tratado com resveratrol). Os animais foram tratados a cada 48 horas tendo início 5 dias antes da cirurgia e mantendo o tratamento até 7 dias depois, por meio de gavagem com $7 \mathrm{mg} / \mathrm{kg}$ de peso corporal de resveratrol, o qual foi diluído em $20 \%$ de álcool de cereais e $80 \%$ de água destilada. Os grupos C, SC e IRC foram tratados apenas com o veículo, uma solução contendo $20 \%$ de álcool de cereais e $80 \%$ de água destilada antes e depois da cirurgia.

Após os animais serem anestesiados com uma mistura de $20 \mathrm{mg} / \mathrm{kg}$ de Xilazina $\mathbb{e}$ e $100 \mathrm{mg} / \mathrm{kg}$ de Ketamina ${ }^{\circledR}$, a injúria por I/R (isquemia seguida de reperfusão) intestinal foi estabelecida por oclusão por 45 minutos da artéria mesentérica superior (AMS) com um clamp microvascular. A isquemia mesentérica foi determinada pela perda da pulsação da artéria mesentérica superior e pela coloração roxa do segmento ileal. Durante o período de reperfusão de 7 dias, os animais permaneceram em gaiolas individuais. Após a eutanásia, realizada com dose letal de $100 \mathrm{mg} / \mathrm{kg}$ de peso corporal de Tiopental Sódico $囚$, foi feita a coleta do segmento a ser estudado que havia sido devidamente delimitado. Após ser lavado em Tampão Fosfato de Sódio (PBS 0,1 M, pH 7,4), $1 \mathrm{~cm}$ do segmento foi macerado e diluído em $4 \mathrm{ml}$ de PBS, e centrifugado à $3000 \mathrm{rpm}$ por 10 minutos. O sobrenadante foi utilizado para quantificação do óxido nítrico, realizada através da reação de Griess, onde foram quantificados os subprodutos nitrato e nitrito; $50 \mu \mathrm{l}$ da solução de Griess (A+B) e $50 \mu \mathrm{l}$ do sobrenadante foram adicionados em placa de Elisa. A leitura foi realizada no leitor de microplacas com comprimento de onda de $570 \mathrm{~nm}$. A curva padrão foi feita utilizando diluições de $\mathrm{NaNO}_{2}$, de $100 \mathrm{mM}$ a $1.56 \mathrm{mM}$. Os resultados foram expressos em $\mu \mathrm{M} / \mathrm{ml}$.

A análise estatística dos dados obtidos foi realizada através do programa GraphPad Prisma v.5, sendo expressos como média \pm erro padrão, com intervalo de confiança de 95 \%. Para a comparação entre os grupos, foram realizadas análises de variância One-way ANOVA, seguida de pós-teste de Tukey. Para ambas as análises o valor de $p$ menor que 0,05 foi considerado estatisticamente significativo.

\section{RESULTADOS E DISCUSSÃO}

Os níveis totais de óxido nítrico encontrados no íleo foram significativamente maiores no grupo IRC em relação ao grupo $C(p<0,001)$ e em relação aos grupos ST e IRT $(p<$ 0,01 ) (Figura 1). O óxido nítrico é sintetizado tanto em condições fisiológicas quanto em condições fisiopatológicas. Embora o ON possua um papel protetor em caso de injúria, 


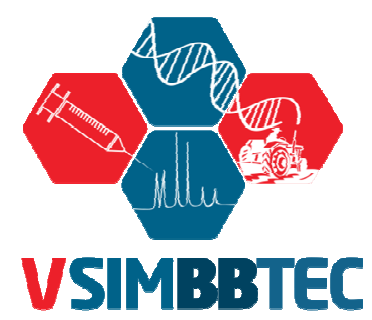

\section{SIMPÓSIO DE BIOQUÍMICA E BIOTECNOLOGIA}

05 a 07 de agosto de 2015, Londrina - PR

Londrina 2015

quando sintetizado em excesso ele pode tornar-se excitotóxico para as células permanecendo em atividade por horas. Esta importante característica é que pode levar à morte da célula em determinadas circunstâncias. (NATHAN; XIE, 1994 e SCHMIDT; WALTER, 1994). A isquemia e reperfusão, além de causar várias outras disfunções, promove um aumento no glutamato extracelular (CALCINA et al., 2005) e a exposição após algumas horas ao glutamato ativa receptores NMDA (N-metil-D-aspartato) que abrem canais permeáveis ao $\mathrm{Ca}^{2+}$. Com o aumento de $\mathrm{Ca}^{2+}$ intracelular, ocorre a ativação da óxido nítrico sintase (NOS), produzindo o radical livre óxido nítrico (ON), o qual reage com espécies reativas de oxigênio (EROs) produzindo o radical peroxinitrito (ONOO-) (RIVERA et al., 2011), sendo este um poderoso agente oxidante que pode causar alterações celulares ou até mesmo levar as células à morte.

Os grupos tratados com resveratrol apresentaram os níveis de ON próximos aos níveis encontrados nos animais do grupo controle, não apresentando diferença significativa entre eles $(p>0,05)$ (Figura 1$)$. O resveratrol pode atuar diretamente na neutralização de radicais livres ou indiretamente modulando a síntese de enzimas antioxidantes (DE LA LASTRA; VILLEGAS, 2007), e promovendo o aumento da captação de glutamato extracelular (QUINCOZES-SANTOS; GOTTFRIED, 2011), o que pode ter contribuído para a redução do ON observada nos animais tratados. Embora o resveratrol também estimule a produção de ON durante a I/R em benefício das células (CHANDER; CHOPRA, 2005), acredita-se que as propriedades anti-inflamatórias e antioxidantes do resveratrol (ZHANG; LIU; SHI, 2010; SGAMBATO et al., 2001) tenham sido capazes de amenizar os danos sofridos pela $I / R$, não sendo necessário o aumento do óxido nítrico na porção distal do íleo dos animais tratados com este polifenol.

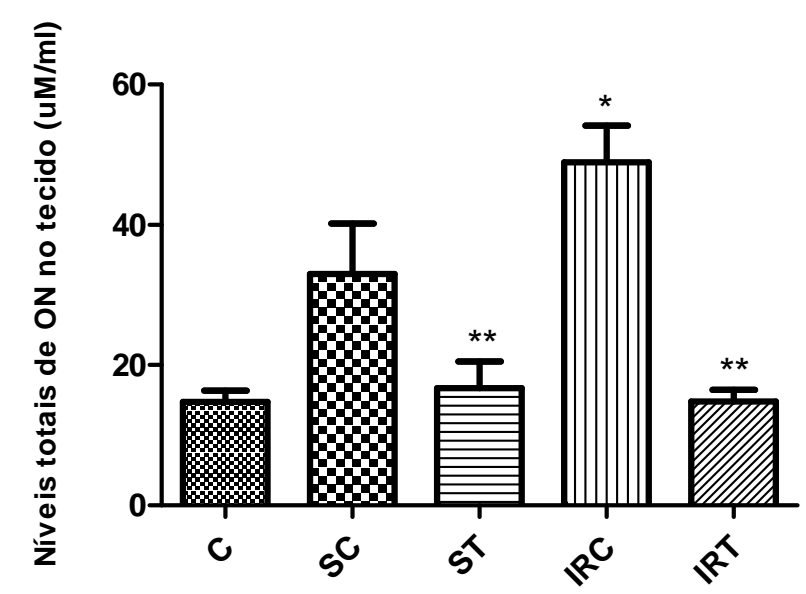

Figura 1 - Níveis totais de óxido nítrico no íleo distal dos grupos controle (C), sham controle (SC), sham tratado (ST), isquêmico controle (IRC) e isquêmico tratado (IRT), expressos em $\mu \mathrm{M} / \mathrm{ml}$. Os valores foram expressos como média \pm erro padrão. *diferença significativa em relação ao grupo controle (C); **diferença significativa em relação ao grupo isquêmico controle (IRC).

\section{CONCLUSÕES}

Embora a isquemia intestinal seguida de reperfusão sanguínea promova o aumento de óxido nítrico presente no tecido ileal, o resveratrol é capaz de agir contra os efeitos nocivos dessa injúria impedindo que o excesso do ON cause maiores danos ao tecido.

Universidade Estadual de Londrina - Rodovia Celso Garcia Cid, Pr 445, Km 380 - Campus Universitário Caixa Postal 10.011 CEP 86057-970 Centro de Ciências Exatas - Departamento de Bioquímica e

Biotecnologia Fone +55 (43) 3371.4270 - biq@uel.br 
Agências de Fomento: Capes e CNPq.

\section{REFERÊNCIAS}

BAUR, J. A; SINCLAIR, D. A. Therapeutic potential of resveratrol: the in vivo evidence. Nat Rev Drug Discov. 2006.

CALCINA, $\mathrm{F}$ et al. Effect of $\mathrm{N}$-methyl-d-aspartate receptor blockade on neuronal plasticity and gastrointestinal transit delay induced by ischemia/reperfusion in rats. Neuroscience. V. 134, p. 39-49, 2005.

CHANDER, V; CHOPRA, K. Role of nitric oxide in resveratrol-induced renal protective effects of ischemic preconditioning. Journal of Vascular Surgery. V. 42, n. 6, 2005.

DE LA LASTRA, C. A; VILLEGAS, I. Resveratrol as an antioxidant and pro-oxidant agent: Mechanisms and clinical implications. Biochem Soc Trans. V. 35, p. 1156-1160, 2007.

FILHO, R. F; ZLBERSTEIN, B. O óxido nítrico como neurotransmissor no sistema nervoso entérico: Fisiopatologia e implicações no íleo adinâmico. v. 25, n. 5, 1998.

FREMONT L. Biological effects of resveratrol. Life Sci. 2000.

KASTE, M. Current therapeutic options for brain ischemia. Neurology. v. 49. P. 49-56, 1997.

KIM, H. K. Experimental models of cerebral ischemia. Acta Anaesthesiol Scand Suppl. 1997.

KÖHLER, H. F; DELUCCA, I. M. S; NETO, L. S. Antioxidantes enterais em lesões de isquemia e reperfusão em ratos. Rev Col Bras Cir. V. 38, n. 6, 2011.

MASSBERG, S; MESSMER, K. The nature of ischemia/ reperfusion injury. Transplant Proc. 1998.

NATHAN, C; XIE, Q. W. Regulation if biosynthesis of nitric oxide. J Biol Chem. v. 26 n. 13, p. 725-728, 1994.

QUINCOZES-SANTOS, A; GOTTFRIED, C. Resveratrol modulates astroglial functions: neuroprotective hypothesis. Ann N Y Acad Sci. 2011.

RIVERA, L. R et al. Deleterious effects of intestinal ischemia/reperfusion injury in the mouse enteric nervous system are associated with protein nitrosylation. Cell Tissue Res. 2011.

SCHMIDT, H. H. H. W; WALTER, U. NO at work. Cell. v. 78, p. 919-925, 1994.

SGAMBATO, A. Resveratrol, a natural phenolic compound, inhibits cell proliferation and prevents oxidative DNA damage. Mutat Res. 2001.

TAKAHASHI, A et al. Intestinal Motility in na In Vivo Rat Modelo f Intestinal Ischemia-Reperfusion With Special Reference to the Effects of Nitric Oxide on the Motility Changes. Journal of Pediatric Gastroenterology and Nutrition. V. 33, n. 3, p. 283-288, 2001.

WANG Q et al. Resveratrol protects against global cerebral ischemic injury in gerbils. Brain Res. 2002.

WANG, Y; MARDSEN, P. A. Nitric oxide synthases: Biochemical andmolecular regulation. Cur Opinion Nephr Hypert. V. 4, p. 12-22, 1995.

ZHANG, F; LIU, J; SHI J. S. Anti-inflammatory activities of resveratrol in the brain: role of resveratrol in microglial activation. Eur J Pharmacol. v. 636, p. 1-7, 2010.

Universidade Estadual de Londrina - Rodovia Celso Garcia Cid, Pr 445, Km 380 - Campus Universitário Caixa Postal 10.011 CEP 86057-970 Centro de Ciências Exatas - Departamento de Bioquímica e Biotecnologia Fone +55 (43) 3371.4270 - biq@uel.br 